\title{
Estimation of Gestational Age by Neurological Assessment in First Week of Life
}

\author{
VALERIE FARR \\ From the Department of Child Health, University of Aberdeen
}

The work of André Thomas in France and Heinz Prechtl in the Netherlands has increased interest in the reflex behaviour of the newborn infant, and the possible diagnostic and prognostic value of neurological assessment in the first week of life. It has been shown that the immature infant is neurologically different from his full-term counterpart and though babies born in the seventh month of pregnancy show nearly all the behaviour patterns of the full-term infant, there are differences in intensity, amplitude, and consistency of the responses (Prechtl, 1965).

In previous studies relating reflex behaviour to gestational age, many of the examinations have been based upon the work of Thomas and Saint-Anne Dargassies (Thomas, Chesni, and Saint-Anne Dargassies, 1960). Geber and Dean (1957) examined African infants weighing more than 2500 g. $\left(5 \frac{1}{2} \mathrm{lb}\right.$.), but in many of them the length of pregnancy was unknown. Horton and Crump (1958) assessed Negro babies and produced a reflex maturity index based on 9 responses, of which 2-motor activity and passive resistance-were found to show some relation to gestational age in the present series. Abramson, Singh, and Mbambo (1961) related their findings to maternal stress and birth weight but not to the length of pregnancy. Brett (1965) estimated fetal maturity in 138 infants. Although the length of pregnancy was not known with certainty in all cases, it was concluded that neurological assessment corresponded closely to obstetrical assessment of gestational age. Illingworth (1963) described a series of tests by which gestational age could be estimated to within 2 weeks, but this method is of greatest value between the 6th and 9th days of life. Many infants, however, are discharged from hospital before this, and if certain reflexes and responses could be elicited satisfactorily at an earlier age, such an examination would be of value, especially in the investigation of infants in maternity hospitals. The

Received November 17, 1967. present study was undertaken to determine whether neurological assessment of maturity is possible as early as the 4th day of life.

\section{Materials and Method}

Cases were selected on the basis of the mother's menstrual history and were only included if she was sure of the date of her last period, which was normal both in duration and amount and which came at the expected time, and she had a regular $28 \pm 2$ day cycle, with no bleeding within a month of the date given for the last period. If at any time during the pregnancy doubt was cast upon the accuracy of the information given, the baby was excluded from the series. If there was doubt about the dates after the baby was born, e.g. if the birthweight was greater or less than would have been expected, the baby was not excluded.

The series comprised 47 male and 35 female infants, ranging in gestational age from 34 to $43 \frac{1}{2}$ weeks, with a mean of 39.4 weeks. Birthweights varied from 14464536 g. ( $3 \mathrm{lb}$. 31 oz. $-10 \mathrm{lb}$.), with a mean of $3062 \mathrm{~g}$. (6lb. $\left.11^{\frac{3}{4}} \mathrm{oz}.\right)$. 60 babies $(73 \%)$ were born by spontaneous vertex delivery, $13(16 \%)$ by caesarean section, $6(7 \%)$ by forceps delivery, and $3(4 \%)$ by breech delivery. None showed clinical evidence of cerebral damage when assessed by the method of Prechtl and Beintema (1964). During the antenatal period, 17 mothers had pre-eclamptic toxaemia, 2 had slight antepartum haemorrhage, and 11 had other disorders such as mild thyrotoxicosis or hypertension. The remaining 52 mothers $(63 \%)$ were well throughout pregnancy.

All babies were assessed by the author without knowing the length of pregnancy. The method of examination was that described by Prechtl and Beintema (1964) for the full-term infant. Reflexes and responses were tested only when the baby was in the optimal state of arousal for each particular test, so that changes in state did not have to be taken into consideration when analysing the results. This strict standardization meant that some babies were excluded from the study because they were not in a suitable state throughout the examination. Each baby was examined an hour before the next feed was due.

Additional tests were also made: these included the maturation reflex (Peiper, 1963), the incidence of 
transient smiling (Silverman, 1961), the degree of closure of the mouth during sucking, head turning to light, and the neck righting reflex.

\section{Results}

The cases were divided initially into 2 groups. Group 1 consisted of those babies whose gestational age was 38 weeks 6 days or less. The mean age was 37.4 weeks ( 1 day $=0.14$ weeks) and the mean weight was 2500 g. $\left(5 \frac{1}{2} \mathrm{lb}\right.$.). Group 2 comprised infants whose gestational age was 39 weeks or more. The mean age was 40.3 weeks and the mean weight 3289 g. (7 lb. $4 \frac{1}{4}$ oz.). The mean Apgar score for each group was $7: 9$ and $8: 9$, respectively (1 minute and 5 minute scoring).

With this grouping there were 21 tests which showed some change in the strength of response with gestational age, and the results of these were analysed further by dividing the cases into smaller gestational groups. As there were few babies of short and prolonged gestation, they were grouped into those of 37 weeks 6 days and less (with a mean age of $36 \frac{1}{2}$ weeks) and those of 41 weeks and more (with a mean of $41 \frac{1}{2}$ weeks). The cases of intermediate gestation were divided into weekly intervals. On this basis the relation to gestational age was not sufficiently clear in 11 of the 21 tests, viz. acoustic blink reflex, Doll's eye test, knee-jerk, palmar grasp, magnet response, withdrawal reflex, traction test, maturation reflex, spontaneous crawling, crossed extensor reflex, and position of the head when prone.

The remaining 10 tests were as follows: (1) spontaneous motor activity; (2) reaction of the pupils to light; (3) rate of sucking; (4) closure of the mouth when sucking; (5) stripping action of the tongue; (6) resistance against passive movement; (7) recoil of the forearm; (8) plantar grasp; (9) pitch of the cry; (10) intensity of the cry. Each of these tests showed a fairly constant change in response with increasing gestational age (Table I).

The percentage of cases showing a particular strength of response was then plotted against gestational age, and a line, corresponding as closely as possible to the various points, was drawn. The 'reflex age' for that response was taken as the gestational age at which this line reached the $90 \%$ level. The assessment was made to the nearest fortnight as it was felt that greater accuracy was not possible when the numbers in each gestational group were not large. The method of calculating the reflex age for weak motor activity is shown in the Fig., and the results for all the responses are shown in Table II. Very few babies showed either absent or marked responses to most of the tests, and these variations in response were not included in the calculations but were placed arbitrarily at the extremes of the scale and are shown in parentheses in Table II.

From this Table, the mean reflex age was estimated for each baby by dividing the sum of the reflex ages by the number of tests made. In most cases all 10 tests were used, but in those where some of the responses could not be elicited satisfactorily, the sum was divided by the appropriate number. Two examples of estimating the mean reflex age are shown in Table III. Although the method of grading the responses had its limitations and was based on a fairly small number of cases in each gestational age-group, the length of gestation was estimated with an error of $2 \frac{1}{2}$ weeks or less in $94 \%$ of cases. There were 11 cases where the examination was incomplete, and in none of these was the error greater than $2 \frac{1}{2}$ weeks. The distribution of error is shown in Table IV. There were 21 cases where gestational age was overestimated and 51 cases where it was underestimated. However, 50 cases $(61 \%)$ were estimated to within 1 week of gestational age calculated from the mother's menstrual data. The mean error was greatest in those below 38 weeks' and above 41 weeks' gestation, i.e. 1.58 and 1.53 weeks, respectively. The error of estimation for all cases was $1 \cdot 15$ weeks (Table V).

\section{Discussion}

Robinson (1966) examined 62 infants whose gestational age could be calculated with reasonable certainty from the maternal menstrual data. Using the method of examination described by Prechtl and Beintema (1964), 10 tests showed a positive correlation with gestational age, but only one of them (the light reflex) was found to be of value in the present series. Robinson found that the neck righting reflex appeared between the 34th and the 37th week and head turning to the light was present after 32-36 weeks' gestation. In the present series, 3 of the 13 babies over 37 weeks' gestation who were tested had an absent neck righting reflex, and 4 of the 17 babies tested who were over 36 weeks did not exhibit head turning to light. The differences in correlation between the various responses and gestational age in Robinsons's study and those in the present series may be due to the fact that Robinson's assessment was based upon the presence or absence of each response. Such an 'all or nothing' method is easier than grading the strength of each response, but it does limit the range of gestational age covered. With Robinson's method it is possible to say that a baby is either less than 31 or more than 34 weeks, 
TABLE I

Distribution of Cases (expressed as percentages) by Intensity of Response and Gestational Age

\begin{tabular}{|c|c|c|c|c|c|c|c|c|c|}
\hline Gestational age (wk.) & & .. & . & $\cdots$ & $<38$ & $38-$ & $39-$ & $40-$ & $\gtrless 41$ \\
\hline Number of cases & . & .. & . & .. & 12 & 15 & 19 & 20 & 16 \\
\hline $\begin{array}{c}\text { (1) Motor activity } \\
\text { Weak .. } \\
\text { Medium } \\
\text { Strong }\end{array}$ & $\begin{array}{l}\ddot{ } \\
\cdots \\
\cdots\end{array}$ & $\begin{array}{l}\cdots \\
\cdots \\
\cdots\end{array}$ & $\begin{array}{l}\cdots \\
\cdots \\
\cdots\end{array}$ & $\begin{array}{l}\cdots \\
\cdots \\
\cdots\end{array}$ & $\begin{array}{r}66 \\
33 \\
0\end{array}$ & $\begin{array}{r}33 \\
66 \\
0\end{array}$ & $\begin{array}{r}5 \\
95 \\
0\end{array}$ & $\begin{array}{r}5 \\
95 \\
0\end{array}$ & $\begin{array}{r}0 \\
100 \\
0\end{array}$ \\
\hline $\begin{array}{c}\text { (2) Pupillary light } \\
\text { Absent } \\
\text { Weak .. } \\
\text { Strong }\end{array}$ & $\begin{array}{l}\text { reflex } \\
\cdots \\
\cdots \\
\cdots\end{array}$ & $\begin{array}{l}\cdots \\
\cdots \\
\cdots\end{array}$ & $\begin{array}{l}\cdots \\
\cdots \\
\cdots\end{array}$ & $\begin{array}{l}\cdots \\
\cdots \\
\cdots\end{array}$ & $\begin{array}{r}0 \\
58 \\
42\end{array}$ & $\begin{array}{r}6 \\
47 \\
47\end{array}$ & $\begin{array}{r}0 \\
39 \\
61\end{array}$ & $\begin{array}{r}0 \\
11 \\
89\end{array}$ & $\begin{array}{r}0 \\
26 \\
74\end{array}$ \\
\hline $\begin{array}{l}\text { (3) Rate of sucking } \\
1-6 \text { sucks }(10 \\
7-14 \text { sucks }(1 \\
15-30 \text { sucks }\end{array}$ & $\begin{array}{l}\text { sec.) } \\
10 \text { sec.) } \\
(10 \text { sec. }\end{array}$ & $\begin{array}{l}\ldots \\
\ldots\end{array}$ & $\begin{array}{l}\cdots \\
\cdots \\
\cdots\end{array}$ & $\begin{array}{l}\cdots \\
\cdots \\
\cdots\end{array}$ & $\begin{array}{r}50 \\
50 \\
0\end{array}$ & $\begin{array}{r}40 \\
60 \\
0\end{array}$ & $\begin{array}{r}7 \\
93 \\
0\end{array}$ & $\begin{array}{r}10 \\
90 \\
0\end{array}$ & $\begin{array}{r}6 \\
94 \\
0\end{array}$ \\
\hline $\begin{array}{l}\text { (4) Closure of mout } \\
\text { Mouth closec } \\
\text { Mouth open }\end{array}$ & $\begin{array}{l}h \text { when } \\
\mathrm{d} \\
\ldots\end{array}$ & $\begin{array}{l}\text { suck } \\
\ldots \\
\cdots\end{array}$ & $\begin{array}{l}. \\
\cdots\end{array}$ & $\begin{array}{l}\cdots \\
\cdots\end{array}$ & $\begin{array}{l}66 \\
33\end{array}$ & $\begin{array}{l}60 \\
40\end{array}$ & $\begin{array}{l}35 \\
65\end{array}$ & $\begin{array}{l}25 \\
75\end{array}$ & $\begin{array}{r}0 \\
100\end{array}$ \\
\hline $\begin{array}{l}\text { (5) Stripping action } \\
\text { Weak ... } \\
\text { Moderate } \\
\text { Strong }\end{array}$ & $\begin{array}{l}\text { of tong } \\
\cdots \\
\ldots \\
\ldots\end{array}$ & $\begin{array}{l}\text { gue } \\
\ldots \\
\ldots \\
\ldots\end{array}$ & $\begin{array}{l}\cdots \\
\cdots \\
\cdots\end{array}$ & $\begin{array}{l}\cdots \\
\cdots \\
\cdots\end{array}$ & $\begin{array}{r}66 \\
33 \\
0\end{array}$ & $\begin{array}{r}46 \\
54 \\
0\end{array}$ & $\begin{array}{r}20 \\
80 \\
0\end{array}$ & $\begin{array}{r}15 \\
85 \\
0\end{array}$ & $\begin{array}{r}18 \\
82 \\
0\end{array}$ \\
\hline $\begin{array}{l}\text { (6) Passive resistanc } \\
\text { Floppy } \\
\text { Weak ... } \\
\text { Medium } \\
\text { Strong }\end{array}$ & $\begin{array}{l}c e \\
\cdots \\
\cdots \\
. \\
.\end{array}$ & $\begin{array}{l}\cdots \\
\cdots \\
\cdots \\
\cdots\end{array}$ & $\begin{array}{l}\cdots \\
\cdots \\
\cdots\end{array}$ & $\begin{array}{l}\cdots \\
\cdots \\
\cdots \\
\cdots\end{array}$ & $\begin{array}{r}0 \\
30 \\
30 \\
40\end{array}$ & $\begin{array}{r}0 \\
0 \\
7 \\
93\end{array}$ & $\begin{array}{r}0 \\
15 \\
0 \\
85\end{array}$ & $\begin{array}{r}0 \\
0 \\
0 \\
100\end{array}$ & $\begin{array}{r}0 \\
0 \\
0 \\
100\end{array}$ \\
\hline $\begin{array}{l}\text { (7) Forearm recoil } \\
\text { Absent } \\
\text { Weak (under } \\
\text { Medium } \\
\text { Strong }\end{array}$ & $\begin{array}{l}\dddot{4} \\
\cdots \\
\cdots\end{array}$ & $\begin{array}{l}\cdots \\
\cdots \\
\cdots \\
\cdots\end{array}$ & $\begin{array}{l}\cdots \\
\cdots \\
\cdots\end{array}$ & $\begin{array}{l}\cdots \\
\cdots \\
\cdots \\
\cdots\end{array}$ & $\begin{array}{r}0 \\
63 \\
37 \\
0\end{array}$ & $\begin{array}{r}0 \\
46 \\
54 \\
0\end{array}$ & $\begin{array}{r}0 \\
34 \\
66 \\
0\end{array}$ & $\begin{array}{r}0 \\
25 \\
75 \\
0\end{array}$ & $\begin{array}{r}0 \\
21 \\
79 \\
0\end{array}$ \\
\hline $\begin{array}{l}\text { (8) Plantar grasp } \\
\text { Absent } \\
\text { Weak .. } \\
\text { Moderate } \\
\text { Strong }\end{array}$ & $\begin{array}{l}. . \\
\cdots \\
\cdots \\
\cdots\end{array}$ & $\begin{array}{l}\ldots \\
\cdots \\
\cdots \\
\cdots\end{array}$ & $\begin{array}{l}\cdots \\
\cdots \\
\cdots \\
\cdots\end{array}$ & $\begin{array}{l}\cdots \\
\cdots \\
\cdots \\
\cdots\end{array}$ & $\begin{array}{r}0 \\
33 \\
66 \\
0\end{array}$ & $\begin{array}{r}0 \\
26 \\
74 \\
0\end{array}$ & $\begin{array}{r}0 \\
15 \\
85 \\
0\end{array}$ & $\begin{array}{r}0 \\
10 \\
90 \\
0\end{array}$ & $\begin{array}{r}0 \\
7 \\
93 \\
0\end{array}$ \\
\hline $\begin{array}{l}\text { (9) Pitch of cry } \\
\text { High .. } \\
\text { Medium } \\
\text { Low .. }\end{array}$ & $\begin{array}{l}. \\
\cdots \\
\cdots\end{array}$ & $\begin{array}{l}\cdots \\
\cdots \\
\cdots\end{array}$ & $\begin{array}{l}\cdots \\
\cdots \\
\cdots\end{array}$ & $\begin{array}{l}\cdots \\
\cdots \\
\cdots\end{array}$ & $\begin{array}{r}33 \\
63 \\
4\end{array}$ & $\begin{array}{l}19 \\
41 \\
40\end{array}$ & $\begin{array}{r}0 \\
40 \\
60\end{array}$ & $\begin{array}{r}5 \\
45 \\
50\end{array}$ & $\begin{array}{r}0 \\
38 \\
62\end{array}$ \\
\hline $\begin{array}{c}\text { (10) Intensity of cry } \\
\text { Low .. } \\
\text { Medium } \\
\text { High .. }\end{array}$ & $\begin{array}{l}. \\
\cdots \\
.\end{array}$ & $\begin{array}{l}\cdots \\
\cdots \\
\cdots\end{array}$ & $\begin{array}{l}\cdots \\
\cdots \\
\cdots\end{array}$ & $\begin{array}{l}\cdots \\
\cdots \\
\cdots\end{array}$ & $\begin{array}{r}67 \\
25 \\
8\end{array}$ & $\begin{array}{r}0 \\
60 \\
40\end{array}$ & $\begin{array}{l}10 \\
55 \\
35\end{array}$ & $\begin{array}{r}0 \\
60 \\
40\end{array}$ & $\begin{array}{r}0 \\
43 \\
57\end{array}$ \\
\hline
\end{tabular}

with a possible extension to between 30 and 36 weeks' gestation. On the other hand, if his method was used in conjunction with the assessment outlined in the present paper, a range of 30 to 42 weeks could be covered. This combination seems to be particularly useful, as the estimation of gestational age in the present series showed greater accuracy between 38 and 41 weeks' gestation.

The tests used in the present study have the practical advantage that they are more readily elicited than most, and none requires much handling of the infant so that the state of arousal is not greatly altered.

The possibility that clinically undetected neurological impairment may affect the results has to be considered. Such impairment might be compensated for by making a more comprehensive neurological examination, but this would make the assessment more time consuming and reduce the chance of maintaining standard conditions.

Problems also arise when the effects of antenatal, natal, and postnatal conditions are taken into 
TABLE II

Estimation of Gestational Age from Selected Neurological Responses

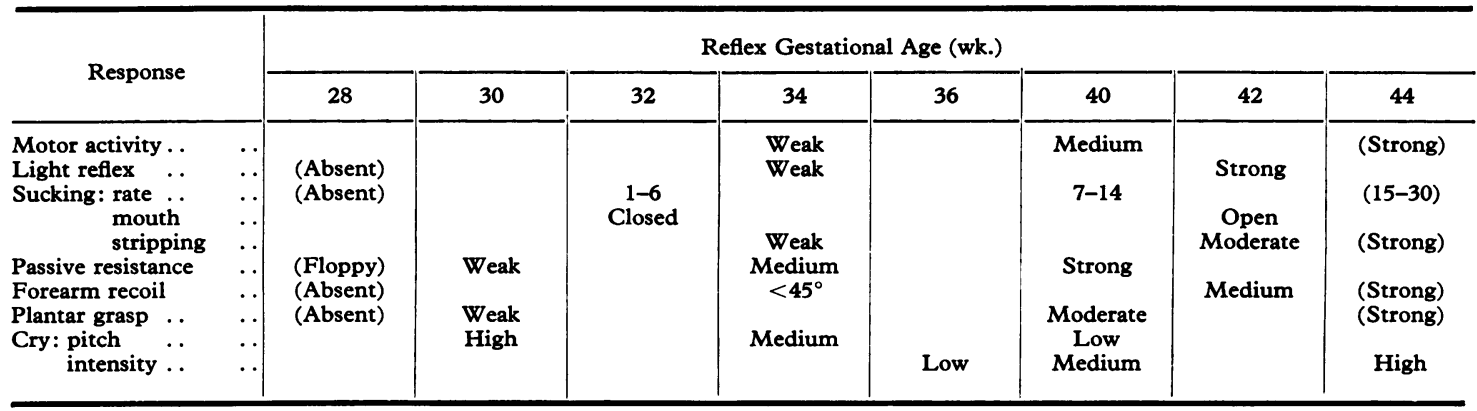

Responses in parentheses are not estimated from the results of the neurological examination as either no infant showed this response or the numbers were too small to make a worthwhile estimation

TABLE III

Cases Illustrating the Estimation of Gestational Age from Selected Neurological Responses

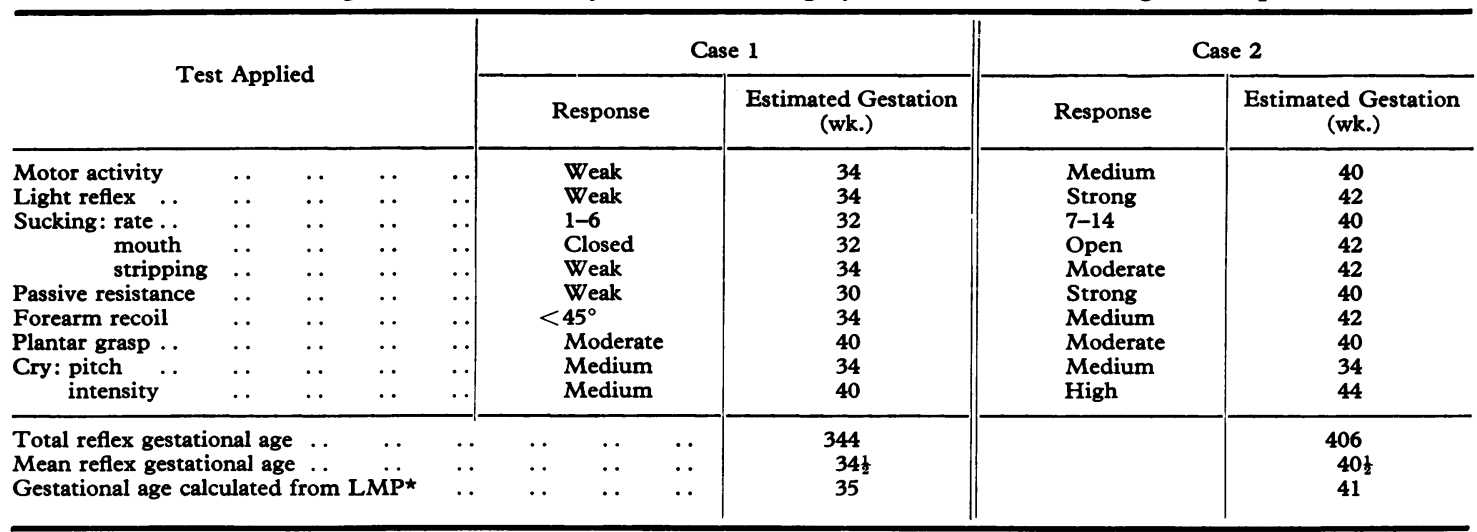

* LMP, the date of the mother's last menstrual period.

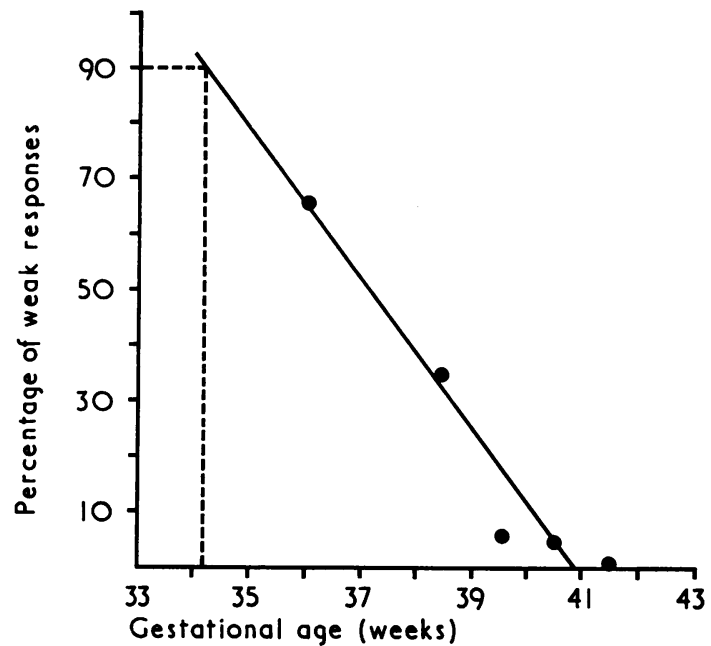

FIG.-The relation between weak motor activity and gestational age, showing the method of calculating the reflex age for this response. 
TABLE IV

Distribution of Error in Estimating Gestational Age by Neurological Assessment

\begin{tabular}{c|c|c|c}
\hline $\begin{array}{c}\text { Error } \\
\text { (wk.) }\end{array}$ & $\begin{array}{c}\text { No. of Cases } \\
\text { Overestimated }\end{array}$ & $\begin{array}{c}\text { No. of Cases } \\
\text { Underestimated }\end{array}$ & Total \\
\hline 0 & - & - & 10 \\
$\frac{1}{2}$ & 11 & 18 & 29 \\
1 & 4 & 7 & 11 \\
$1 \frac{1}{2}$ & 3 & 6 & 9 \\
2 & 0 & 11 & 11 \\
$2 \frac{1}{2}$ & 1 & 6 & 7 \\
3 & 1 & 2 & 3 \\
$3 \frac{1}{2}$ & 0 & 1 & 1 \\
4 & 1 & 0 & 82 \\
\hline Total & 21 & 51 & \\
\hline
\end{tabular}

TABLE V

Mean Error in Estimating Gestational Age at Different Stages of Gestation

\begin{tabular}{|c|c|c|c|c|c|}
\hline \multicolumn{4}{|c|}{$\begin{array}{l}\text { Period of Gestation } \\
\text { (wk.) }\end{array}$} & $\begin{array}{l}\text { No. of } \\
\text { Cases }\end{array}$ & $\begin{array}{l}\text { Mean Error } \\
\text { (wk.) }\end{array}$ \\
\hline $\begin{array}{l}\text { Under } 38 \\
38- \\
39- \\
40- \\
41 \text { and over }\end{array}$ & $\begin{array}{l}\cdots \\
\cdots \\
\cdots \\
\cdots\end{array}$ & $\begin{array}{l}\cdots \\
\cdots \\
\cdots \\
\cdots\end{array}$ & $\begin{array}{l}\cdots \\
\cdots \\
\cdots \\
\cdots \\
\cdots\end{array}$ & $\begin{array}{l}12 \\
15 \\
19 \\
20 \\
16\end{array}$ & $\begin{array}{l}1 \cdot 58 \\
1 \cdot 43 \\
0 \cdot 81 \\
0 \cdot 82 \\
1 \cdot 53\end{array}$ \\
\hline Total & . & $\ldots$ & $\ldots$ & 82 & $1 \cdot 15$ \\
\hline
\end{tabular}

account, since these must affect some, if not all, of the tests. Nevertheless, if neurological assessment is to be of value it must be applicable to the majority of infants and not only to selected normals.

Although the number of infants in the present study was not large, it is concluded that certain neurological tests show changes in response with increasing gestational age, and some of these changes are sufficiently constant for them to be used in the estimation of gestational age, despite the instability of the neonate's central nervous system during the first few days of life.

\section{Summary}

Eighty-two infants were examined neurologically on the fourth day of life, according to the method described by Prechtl and Beintema (1964), and the results were related to the length of gestation. Not all reflexes and responses showed changes with variation in age, but 10 tests were selected and a method of assessing 'reflex gestational age' was evolved. The results showed a close correlation with the length of pregnancy as estimated from the mother's menstrual data, the assessment being correct to within $\pm 2 \frac{1}{2}$ weeks in $94 \%$ of cases. Previous studies on neurological assessment have been reviewed briefly and the limitations of this method of estimating maturity discussed. It is concluded that the neurological assessment of gestational age is of value, but further studies are needed before a satisfactory and readily applicable method is achieved.

\section{REFERENCES}

Abramson, J. H., Singh, Ansuyah R., and Mbambo, V. (1961). Antenatal stress and the baby's development. Arch. Dis. Childh., 36, 42.

Brett, E. M. (1965). The estimation of foetal maturity by the neurological examination of the neonate. Little Club Clin. develop. Med., 19, 105.

Geber, M., and Dean, R. F. A. (1957). The state of development of newborn African children. Lancet, 1, 1216.

Horton, C. P., and Crump, E. P. (1958). Growth and development. III. Skin color in negro infants and parents. $\mathcal{7}$. Pediat., 52, 547.

Illingworth, R. S. (1963). The Development of the Infant and Young Child, Normal and Abnormal, 2nd ed., p. 251. Livingstone, Edinburgh and London.

Peiper, A. (1963). Cerebral Function in Infancy and Childhood, 3rd ed. Consultant's Bureau, New York.

Prechtl, H. F. R. (1965). Problems of behavioral studies in the newborn infant. In Advances in the Study of Behaviour, Vol. 1. Ed. by D. S. Lehrman, R. A. Hinde, and E. Shaw. Academic Press, New York and London.

- , and Beintema, D. (1964). The neurological examination of the full-term newborn infant. Little Club Clin. develop. Med., 12.

Robinson, R. J. (1966). Assessment of gestational age by neurological examination. Arch. Dis. Childh., 41, 437.

Silverman, W. A. (1961). Dunham's Premature Infants, 3rd ed. Hoeber, New York.

Thomas, A., Chesni, Y., and Saint-Anne Dargassies, S. (1960). The neurological examination of the infant. Little Club Clin. develop. Med., 1. 